\title{
Necrose Cutânea Grave Induzida por Varfarina
}

\author{
Serious Skin Necrosis Induced by Warfarin
}

Joana CARLOS-ALVES ${ }^{1}$, Inês Fernandes SOARES ${ }^{1}$, João Pedro CRUZ ${ }^{1}$, António FERREIRA ${ }^{1}$ Acta Med Port 2013 Sep-Oct;26(5):621-621

Palavras-chave: Doenças da Pele/induzidas quimicamente; Erupção por Medicamentos; Varfarin/efeitos adversos.

Keywords: Drug Eruptions; Skin Diseases/chemically induced; Warfarin/adverse effects.

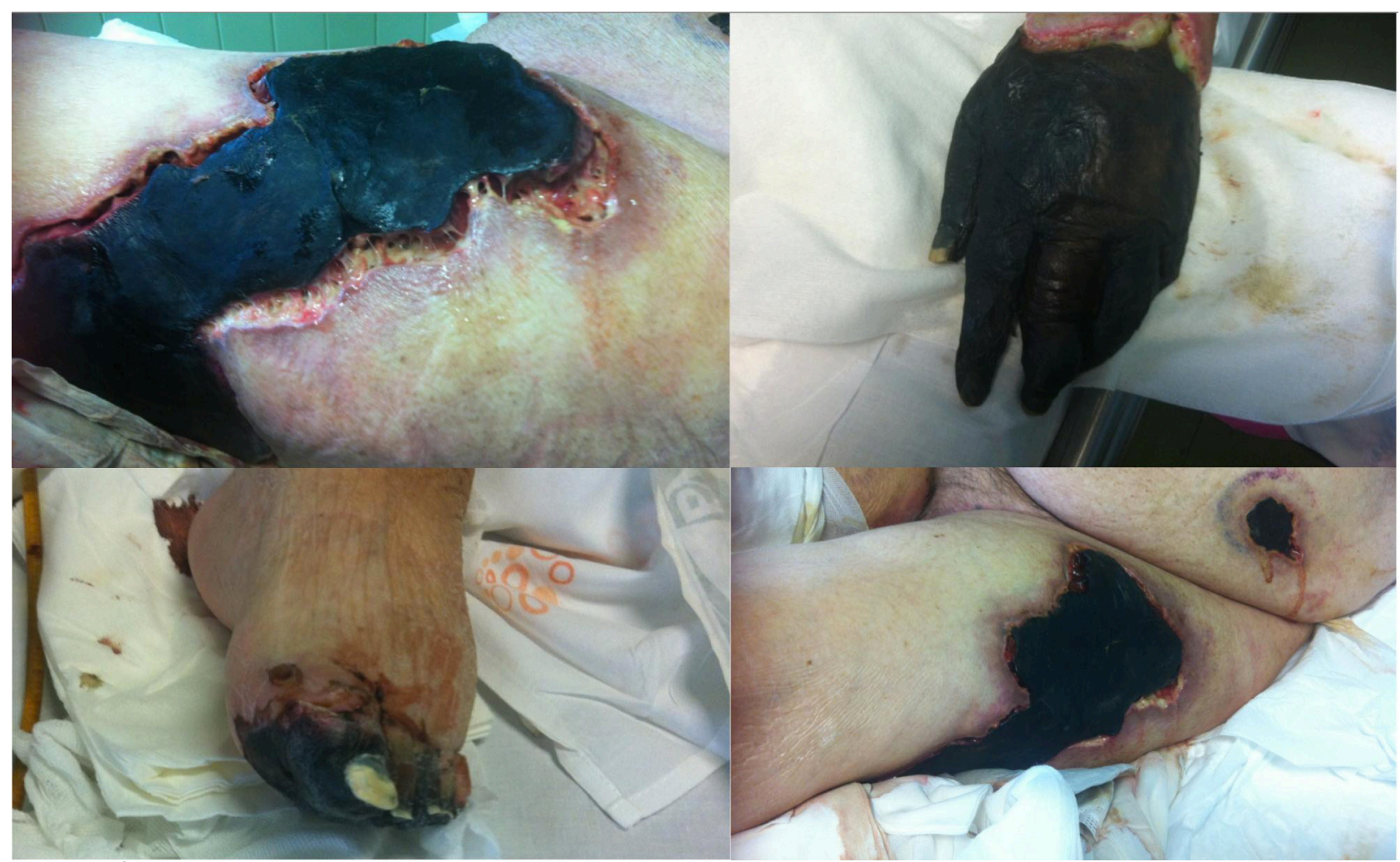

Figura 1 - Áreas extensas de necrose cutânea grave.

Sexo feminino, 81 anos, antecedentes de acidente vascular isquémico extenso, epilepsia e demência.

Medicada com Fenitoína e Varfarina com início sete dias antes por tromboembolismo pulmonar.

Recorre ao Serviço de Urgência por febre e alteração do estado de consciência. A doente encontrava-se prostrada e com desorientação temporo-espacial. Ao exame objetivo apresentava $\mathrm{T}^{\mathrm{a}} 38^{\circ} \mathrm{C}$ e zonas de pele com áreas eritematosas e necróticas. Os exames complementares revelaram leucocitose com neutrofilia e INR de 12,9. Internada no ser-

viço de Medicina e pedida colaboração de Dermatologia que descreveu múltiplas lesões cutâneas e subcutâneas extensas com bordo inflamatório e coxa esquerda com áreas de necrose com descolamento cutâneo e pele exsudativa - compatível com necrose cutânea secundária a Varfarina. Suspendeu o fármaco, iniciou vitamina $\mathrm{K}$ e antibioterapia de amplo espetro. Decidiu-se pelo desbridamento cirúrgico e amputação das áreas desvitalizadas. ${ }^{1-4}$

Apresentou evolução desfavorável no contexto de disfunção multiorgânica, falecendo ao $10^{\circ}$ dia de internamento.

\section{REFERÊNCIAS}

1. Grim S, Sopkovich J, Dean S, Zirwas M. Warfarin-induced venous limb gangrene. J Clin Aesthet Dermatol. 2012;5:38-42.

2. Ward CT, Chavalitanonda N. Atypical warfarin-induced skin necrosis. Pharmacotherapy. 2006;26:1175-9.

3. Mungalsingh C, Bomford J, Nayagam J, Masiello M, Ekeowa U, Webster S. Warfarin-induced skin necrosis. Clin Med. 2012;12:90-1.

4. Kaiber F, Baroni E, Akamatsu H, Malucelli T, Schafranski M, Schmidt C. Heparin-induced thrombocytopenia and warfarin-induced skin necrosis: case report. An Bras Dermatol. 2010;85:915-8.

1. Serviço de Urgência. Centro Hospitalar de Trás-os-Montes e Alto Douro. Unidade de Chaves (CHTMAD). Chaves. Portugal.

Recebido: 06 de Fevereiro de 2013 - Aceite: 04 de Maio de 2013 | Copyright @ Ordem dos Médicos 2013 